\title{
Effects of Reading a Picture Leaflet on Rhythm for Enhancement of Morning-Typed Life in Japanese Infants
}

\author{
Misako Kawamata1, Ryota Kawasumi' ${ }^{1}$, Fujiko Tsuji'1, Nozomi Taniwaki², Takahiro Kawada1,3, \\ Teruki Noji ${ }^{3}$, Milada Krejci ${ }^{4}$, Miyo Nakade5, Hitomi Takeuchi' ${ }^{1}$, Tetsuo Harada ${ }^{*}$ \\ ${ }^{1}$ Laboratory of Environmental Physiology, Graduate School of Integrated Arts and Sciences, Kochi University, Kochi, Japan \\ ${ }^{2}$ Kindergarten affiliated to Faculty of Education, Kochi University, Kochi, Japan \\ ${ }^{3}$ Center for Regional Collaboration, Kochi University, Kochi, Japan \\ ${ }^{4}$ University of Physical Education and Sports PALESTRA in Prague, Czech Republic \\ ${ }^{5}$ Faculty of Health and Nutrition, Tokai-Gakuen University, Nagoya, Japan \\ Email: ^haratets@kochi-u.ac.jp
}

How to cite this paper: Kawamata, M., Kawasumi, R., Tsuji, F., Taniwaki, N., Kawada, T., Noji, T., Krejci, M., Nakade, M., Takeuchi, H., \& Harada, T. (2017). Effects of Reading a Picture Leaflet on Rhythm for Enhancement of Morning-Typed Life in Japanese Infants. Psychology, 8, 1621-1641. https://doi.org/10.4236/psych.2017.811107

Received: June 5, 2017

Accepted: August 28, 2017

Published: August 31, 2017

Copyright () 2017 by authors and Scientific Research Publishing Inc. This work is licensed under the Creative Commons Attribution International License (CC BY 4.0).

http://creativecommons.org/licenses/by/4.0/

\begin{abstract}
In this study, a teaching material as a picture leaflet for infant was made, and the educational effectiveness of the leaflet was examined on the infants who attend one of ten nursery schools or a Kindergarten affiliated to Faculty of Education, Kochi University. The title of the picture leaflet is "A picture book on diurnal rhythm! Let's take cow milk breakfast and become a morning-typed person!” (Seikatsu-rizumunoehon, gyunyudehayanehayaoki: in Japanese). An intervention study was performed using an integrated questionnaire. The questionnaire before the intervention was administered and parents of 820 infants ( 711 ones attending one of the 10 nursery schools and 109 ones attending the Kindergarten) answered the questionnaire instead. All parents were asked to read the picture leaflet to their children every day during three weeks intervention period of June, 2016. Ratio of infants who had the reading of the leaflet more than 1 time for the 3 weeks was $94.5 \%$ and the average days when the reading of it was performed was 10.8 days. More than half of parents (52.4\%) performed the reading it more than 10 days. Eleven percent (18 parents) of parents performed the reading every day of 21 intervention-days. In the first week of intervention, about 60\% (97 infants) of the parents performed the reading in more than 4 days. Infants who had the reading it from their parents everyday got up in earlier time significantly than those who did it not in every day (U-test, $\mathrm{z}=-4.33, p<0.01$ ). Infants who had the reading of it every day went to bed in earlier time than the other ones who did it not in every day (U-test, $\mathrm{z}=-7.731, p<0.001$ ), and they slept more hours than the other ones (U-test, $\mathrm{z}=-2.30, p<0.001$ ). In conclusion, the reading of a picture leaflet which recommends a morning-typed life seems to be effective for
\end{abstract}


infants to promote the morning-typed life and quality of life (QOL) even though the intervention period is short as three weeks.

\section{Keywords}

A Picture Leaflet as a Teaching Material, Small Children Aged 2 - 6 Years Old, Morningness-Eveningness, Intervention Study, Protein Resources at Breakfast

\section{Introduction}

This study tries to clarify whether a new leaflet (Appendix 1 and Appendix 2) for infants, which was newly evaluated for small Japanese children. Before the methodology and results in this study will be described, it is introduced how the researchers have been performed on the breakfast and mental health (1-1), body math (1-2), school bullying (1-3), academic achievements (1-4), total health (1-5), breakfast-education and breakfast-supplying program (1-6), breakfast-skipping problem (1-7) and evaluation of a teaching material for breakfast (1-8), for children so far.

\subsection{Breakfast and Mental Health in Children}

Breakfast seems to be very important for promoting children's mental health. For example, better mental health can be promoted by the nutritionally rich breakfast (including protein resource as tryptophan supply: Harada et al., 2007; Nakade et al., 2009, 2012; Harada et al., 2012; Wada et al., 2013) based on basic questionnaire studies and intervention studies. On the relationship between the mental health and the frequency to take breakfast in Korea, the data were obtained from the 2013 Korean Community Health Survey; a total of 207,710 survey participants aged 20 years or over were studied. Participants were categorized into three groups by the frequency of breakfast consumption as follows: "seldom," "sometimes," and "always." (Lee et al., 2017). Participants who had breakfast seldom or sometimes had higher depressive symptoms than those who always ate breakfast. In an interview report for elementary school students, the omission rate, intrusion rate, and inflation ratio were greater in the case of breakfast skipping than for lunch skipping (Baxter et al., 2007).

\subsection{Breakfast and Obesity or Body Mass Index (BMI)}

The effect of breakfast and breakfast omission on daily food intake in normal and overweight participants was investigated (Reeves et al., 2014). All groups consumed significantly less energy, carbohydrate and fibre in the no breakfast week; however, overweight participants increased their sugar intakes. The findings highlight that the timing of food intake and habitual breakfast eating behavior are important factors when investigating why breakfast consumption may be associated with BMI. Nakade et al. (2015) showed that there was negative correlation between the diurnal type scores (lower scores mean evening-type) and body 
mass index in mothers of Japanese infants.

Also in Japan, the objective of the present study was to evaluate the acute effects of skipping breakfast (SB) on energy intake and physical activity under free-living conditions. The present study used a randomized, crossover trial design comparing eating breakfast (EB). Skipping breakfast reduced energy intake during the day and morning physical activity in healthy women who were habitual breakfast eaters. The decreased energy expenditure related to physical activity after SB did not exceed the decreased energy intake which may lead to higher BMI (Yoshimura et al., 2017).

Another USA breakfast supplying program as the break FAST study successfully recruited 16 rural high schools and exceeded enrolling and measuring a cohort of students at baseline, including 30\% minority students, into a randomized clinical trial. At the conclusion of the break FAST study, an intervention was effective in changing behavior and nutrition outcomes (nutritional quality of diet, BMI, and percent body fat) among students (Nanney et al., 2016).

\subsection{Breakfast Which May Be Related to Cyberbullying and School Bullying}

Self-reported data about Canadian children's experiences (11 - 20 years old) showed that $26.3 \%$ and $24.1 \%$ reported often (usually eat breakfast three times or more per week) and frequent (usually eat breakfast twice a week or less) breakfast skipping behavior, respectively (Sampasa-Kanyinga et al., 2014). Victims of both cyberbullying and school bullying presented greater likelihood of often (adjusted relative risk ratio $(\mathrm{RR})=1.55 ; 95 \%$ confidence interval $(\mathrm{CI})=$ 1.17 - 2.06) and frequent $(\mathrm{RR}=1.97 ; 95 \% \mathrm{CI}=1.28$ - 3.03) breakfast skipping.

\subsection{Breakfast and Academic Achievement in Schools}

In Korea, a cross-sectional data on a sample of 1652 high-school seniors (942 males and 710 females) drawn from the 2004 Korea Education Employment Panel were analyzed. Females who skipped breakfast had a lower probability of having the highest scores in language (OR Z 0.41, $p<0.05$ ), mathematics (OR Z $0.24, p<0.01$ ), or foreign language ( $\mathrm{OR} \mathrm{Z} 0.18, p<0.01$ ), while males had a lower probability of having the highest scores in language only (OR Z $0.46, p<$ 0.05) (Kang and Park, 2016). A cross-sectional study consisted of a sample of 1269 children (697 boys and 572 girls) aged 6 years from the Chinese city of Jintan. Findings showed that children who regularly have breakfast on a near-daily basis had significantly higher full scale, verbal, and performance IQ test scores (all pb 0.001) compared to children who "sometimes" have breakfast (Liu et al., 2013). Recently in Japan, elementary school children who had sleep hours gen erally longer than 9 hours showed clearly higher markings in Japanese language than those who had slept only less than 9 hours (Takeuchi et al., 2017).

\subsection{Breakfast and Total Health of Children}

As a role of breakfast in health in USA, definition and criteria for a quality 
breakfast was shown by O'Neil et al. (2014). According to the "Research Commentary" of this reference, there have been evidences that consumption of a breakfast meal was positively associated with general health and well being for both adults and children, suggesting the need to elevate the importance of breakfast in dietary guidance and nutrition education and communications.

\subsection{Breakfast Supplying Program in School and On-Line Breakfast Education}

Supplying breakfast seems to be an effective method for children to have breakfast with full nutrition certainly. Several examples have been performed so far as follows. As an breakfast supplying program in South Africa, an evaluation included a three-phase approach to establish a baseline of learners in relation to performance and nutritional status; an interim phase; and final phase to ascertain any changes after the introduction of the breakfast programme. Triangulation of the anthropometric and qualitative research suggests that children benefitted from the public-private social investment scheme (Hochfield et al., 2016). In USA, a School Breakfast Program (SBP) was performed for cognitive achievement (Frisvold, 2015). The SBP is a federal entitlement program that offers breakfast to any student, including free breakfast for any low-income student, who attends a school that participates in the program. Using the details of these mandates as a source of identifying variation, it was found that the availability of the program increased student cognitive achievement. Online education program was performed and it was effective in comparison with in-person education for increased frequency to take breakfast for children to examine the influences of online and in-person group nutrition education on changes in knowledge, attitudes, and behaviors related to breakfast eating (Au et al., 2016). Increases in the frequency of eating breakfast were greater for both the parents ( $p$ $=0.0007)$ and child $(p=0.01)$ in the online group education group compared with the in-person group education during the same time points.

\subsection{Factors to Be Related to the Breakfast Skipping in Children}

For promoting taking nutritionally rich breakfast for children, attitudes, parental descriptive norms and clustering at school level are reported to be important and also related to breakfast skipping (Moore et al., 2009). In this study, participants were 1672 year 5 and 6 pupils within 52 schools in 9 local education authorities across North, South and West Wales. In multivariate ordinal logistic regression analyses, adjusted for clustering at the school-level, only attitudes towards breakfast, parental descriptive norms and self-efficacy for eating breakfast were significantly associated with breakfast skipping (Moore et al., 2009).

\subsection{A Teaching Material of a Picture Book for Young Children}

Tryptophan included in proteins taken at breakfast seems to become resource for morning synthesize of serotonin in the morning based on the resent research (Harada et al., 2007). Serotonin can be affective for promoting mental health and 
also can be an inner zeitgeber for circadian clocks of human (Nakade et al., 2009). The serotonin can be synthesized into melatonin at night in pineal which promotes fall-in-sleep at night. Protein which was consumed at breakfast could be effective for promoting the mental health through another synthesis from thyroxin and phenylalanine into dopamine in Japanese infants (Akimitsu et al., 2013). Consumption of cow milk at morning can promote the shifting of the diurnal rhythms of infants and university athletes and promote their sleep health (Takeuchi et al., 2014; Harada et al., 2015; Kawada et al., 2016 a, b).

The significance of the research from practical social significance is that a new teaching material as "picture book" and academic significance, these two aspects are important for research significance.

A direct teaching material like as a picture leaflet for promoting "morning-typed life and taking nutritionally rich breakfast" might be effective for especially small children attending kindergarten and elementary schools. However, there have been no such teaching materials for small children so far. However, direct and familiar teaching subjects for promoting the health of infants through morning consumption of cows' milk and following morning-typed life style have not been evaluated yet. In this study, a teaching material as a picture leaflet for infant was made, and the educational effectiveness of the leaflet was examined on the infants who attend ten nursery schools and a Kindergarten affiliated to Faculty of Education, Kochi University. The title of the picture leaflet is "A picture book on diurnal rhythm! Let's take cows' milk at breakfast and become a morning-typed person!" (Seikatsu-rizumunoehon, gyunyudehayanehayaoki: in Japanese).

\section{Methods}

\subsection{Participants and Instruments}

A picture leaflet was newly made entitled "A picture book on diurnal rhythm! Let's take cows' milk in the morning and become morning-typed persons!" (Appendix 1 and Appendix 2).

An intervention study was performed using an integrated questionnaire. The questionnaire (Harada et al., 1998; Takeuchi et al., 2014, 2015) before the intervention was administered and parents of 820 infants (Table 1) (711 ones attending one of 10 nursery schools and 109 ones attending a Kindergarten affiliated to Faculty of Education, Kochi University) answered the questionnaire instead. The questionnaire included questions on sleep habits, mental conditions (anger, irritation, out-of-control of emotion, depression), the Diurnal Type Scale (DTS) (Torsvall \& Ákerstedt, 1980), meal habits, and light environments (Harada et al., 1998). All parents who were asked to read the picture leaflet everyday during three weeks intervention period of June, 2016. A questionnaire on breakfast contents and sleep onset and offset which was shown by Table 2 was administrated to the parents during the intervention 3 weeks. Only $20 \%$ of the participants attending in 10 nursery schools and one kindergarten filled with the 
Table 1. The number of participants for questionnaire study before intervention and the following intervention.

\begin{tabular}{cccccc}
\hline & Distribution & Answer & $\begin{array}{c}\text { Rate to } \\
\text { answer }\end{array}$ & $\begin{array}{c}\text { Number for } \\
\text { analysis }\end{array}$ & $\begin{array}{c}\text { Answer rate } \\
\text { for analysis }\end{array}$ \\
\hline $\begin{array}{c}\text { Nursery } \\
\text { schools }\end{array}$ & 711 & 152 & 21.38 & 108 & 15.19 \\
$\begin{array}{c}\text { Kindergarten } \\
\text { In total }\end{array}$ & 109 & 74 & 67.89 & 56 & 51.38 \\
& 820 & 226 & 27.56 & 164 & 20 \\
\hline
\end{tabular}

Table 2. A questionnaire during the intervention period of 3 weeks.

\section{Sheet for checking several habits during the intervention}

Please write down wake up time and go to bed time every day. On the breakfast your child (children) took, you can write every day whether the three components of carbohydrates, main dish (protein resource) and cows' milk. You can write down every day whether you performed the reading of the picture book distributed.

$\circ$ : Yes; $\times$ : No,

\begin{tabular}{|c|c|c|c|c|c|c|c|c|c|c|c|c|}
\hline & & June 16 & 17 & 18 & 19 & 20 & 21 & 22 & 23 & 24 & 25 & 26 \\
\hline \multicolumn{13}{|c|}{ Wake up time } \\
\hline \multicolumn{13}{|c|}{ Carbohydrate } \\
\hline \multirow[t]{2}{*}{ Breakfast } & Main dish & & & & & & & & & & & \\
\hline & Cow milk & & & & & & & & & & & \\
\hline \multicolumn{13}{|c|}{ Reading performance } \\
\hline \multicolumn{13}{|c|}{ Bed-in-time } \\
\hline & & June 27 & 28 & 29 & 30 & July 1 & 2 & 3 & 4 & 5 & $\begin{array}{r}\text { Num } \\
\text { in }\end{array}$ & $\begin{array}{l}\mathrm{r} \text { of } \bigcirc \\
\mathrm{tal}\end{array}$ \\
\hline \multicolumn{13}{|c|}{ Wake up time } \\
\hline \multicolumn{13}{|c|}{ Carbohydrate } \\
\hline \multirow[t]{2}{*}{ Breakfast } & Main dish & & & & & & & & & & & \\
\hline & Cow milk & & & & & & & & & & & \\
\hline \multicolumn{13}{|c|}{ Reading performance } \\
\hline \multicolumn{13}{|c|}{ Bed-in-time } \\
\hline \multicolumn{13}{|c|}{ Example of foods } \\
\hline \multicolumn{13}{|c|}{ 1. Carbohydrate: bread, boiled rice, noodle, serial etc } \\
\hline \multicolumn{13}{|c|}{ 2. Main dish: fishes, meats, soy beans, fermented beans and tofu, ham and sausage etc. } \\
\hline \multicolumn{13}{|c|}{ 3. Cow milk and milk products: cow milk, cheese and yogurt etc. } \\
\hline \multicolumn{13}{|c|}{ \# Please check the sheet, which can be put on your refrigerator for 3 weeks from 14th June to 4 th July 2017} \\
\hline \# We can co & he sheet which & een filled & h you & 10th & ly 20 & which w & hede & . & & & & \\
\hline
\end{tabular}

questionnaire through the 3 intervention periods. The questionnaire as a life habit diary consists of bedtime, wake up time, breakfast contents, whether the reading of the picture leaflet was performed in each of the intervention 3 weeks. The question on breakfast contents was whether infants take nutritionally good breakfast including the three items: carbohydrates, protein, and cows' milk (Table 2). 


\subsection{Statistic Analysis}

The questionnaire data was analyzed with SPSS 12.0 statistical software. The categorized data in the diary data were analyzed using Fisher's exact probability test. Mann-Whitney U-test (data in order-categorized data) and $x^{2}$-test (categorized data-categorized data) were used for non paired data in this study.

\subsection{Ethic Treatment}

The study followed the guidelines established by the Chronobiology International journal for the conduct of research on human subjects (Portaluppi et al., 2010). Before administrating the questionnaires for this intervention study, each participant (parents or guardians) was given a written explanation that detailed the concepts and purposes of the study and stated that their answers would be used only for academic purposes. After the above explanation, all parents (or guardians) agreed completely with the proposal. The study was also permitted by the kindergarten nurses' committees of the ten nursery schools and one kindergarten which carried out an ethical inspection of the contents of the questionnaire. As the young children could not complete the questionnaires themselves, their parents or guardians completed them on their behalf.

\section{Results}

Sleep habits in October, 2017, 3 months after the intervention were quite similar to those in June, 2017 just before the intervention with no significant differences $(p>0.05)$. Average of the DTSs before and after the intervention were 20.8 and 20.7, respectively, which are similar values without no significant differences.

Sixty and zero-point-seven percent of the parents (152 of the nursery schools and 74 of the kindergarten answered it) to whom the questionnaire was distributed, answered the question as the diary through the intervention 3 weeks. Twenty seven and zero-point-six percent (226/820) of the parents in which their infants attended one of 10 nursery schools and the Kindergarten answered the questionnaire consisting several questions during the intervention 3 weeks. On the intervention study, 164 answers which complete ones were used for analysis (Table 2). Forty seven percent of mothers read this picture leaflet to their children for 4 - 7 days per one week during the 3 weeks intervention period (Table 3 ). Only $20 \%$ of the participants attending in 10 nursery schools and one kindergarten filled with the questionnaire through the 3 intervention periods. The data of the $20 \%$ can be thought to show the data by the parents who kept relatively higher consciousness on their own children and their education. This point might be a limitation of this study. In the near future, another strategy should be evaluated for collecting data also from the parents who have lower consciousness on the education of their children.

Ratio of infants who had the reading of the leaflet more than 1 time for the 3 weeks was $94.5 \%$ and the average days when the reading of it was performed was 10.8 days. More than half of parents (52.4\%) performed the reading it more than 
Table 3. How many number (\%) of participants were interpreted as read by parents of the leaflet in each of three weeks intervention period.

\begin{tabular}{cccc}
\hline Intervention days & week 1 & week 2 & week 3 \\
\hline No interpretation days & 13 & 29 & 27 \\
& $(7.93)$ & $(17.68)$ & $(16.46)$ \\
$\mathbf{1}-\mathbf{3}$ days & 54 & 57 & 60 \\
& $(32.93)$ & $(34.76)$ & $(36.59)$ \\
$4-7$ days & 97 & 78 & 77 \\
& $(59.15)$ & $(47.56)$ & $(46.95)$ \\
\hline
\end{tabular}

10 days. Eleven percent (18 parents) of parents performed the reading every day of 21 intervention-days (Figure 1). In the first week of intervention, about $60 \%$ (97 infants) of the parents performed the reading in more than 4 days (Table 3 ).

Infants who had the reading it from their parents everyday got up in earlier time significantly than those who did it not in every day (U-test, $\mathrm{z}=-4.33, p<$ 0.01 ) (Figure 2). Infants who had the reading it went to bed in earlier time than the other ones who did it not in every day (U-test, $\mathrm{z}=-7.731, p<0.001$ ) (Figure 3 ), and they slept more hours than the other ones ( $\mathrm{U}$-test, $\mathrm{z}=-2.30, p<0.001$ ) (Figure 4). Infants who had the reading it from their parents every day got main dish (protein resource) in more days (Fisher's exact test, $p=0.021$ ) and took cows' milk at breakfast in more days (Fisher's exact test, $p<0.001$ ) than the other ones.

Wake up time (U-test, $\mathrm{z}=-3.30, p=0.001$ ) (Figure 5) and bed-in time (U-test, $\mathrm{z}=-3.94, p<0.001$ ) (Figure 6) in the next day of the day when the reading of the picture leaflet was performed were earlier than those in the days next to the days when the reading was not performed. Sleep hours (U-test, $\mathrm{z}=$ $-2.25, p=0.024$ ) (Figure 7) were significantly longer in the next days of the days when the picture leaflet was read, than the other days. The frequencies to take main dish (protein resource) (Fisher's exact test, $p<0.001$ ) (Figure 8(a)) and cows' milk (Fisher's exact test, $p<0.001$ ) (Figure $8(\mathrm{~b})$ ) were higher in the next days of the days when the reading it was performed than those in the other days.

\section{Discussion}

About $50 \%$ of the parents (mainly mothers) implemented the reading of the picture leaflet to their children on the 12 - 21 days during the 21 days intervention period. Reading the picture leaflet may prohibit the children to get up later than 7:30 and also may prohibit them to go to bed later than 21:00. As the result, this leaflet can make the children to have sleep hours longer than 10. 5 hours from this result. Together with the daytime sleep about 2 hours in the nursery schools, the total sleeping hours could be elongated up to more than 12.5 hours after the effects of reading this picture leaflet in this study. On average, the 


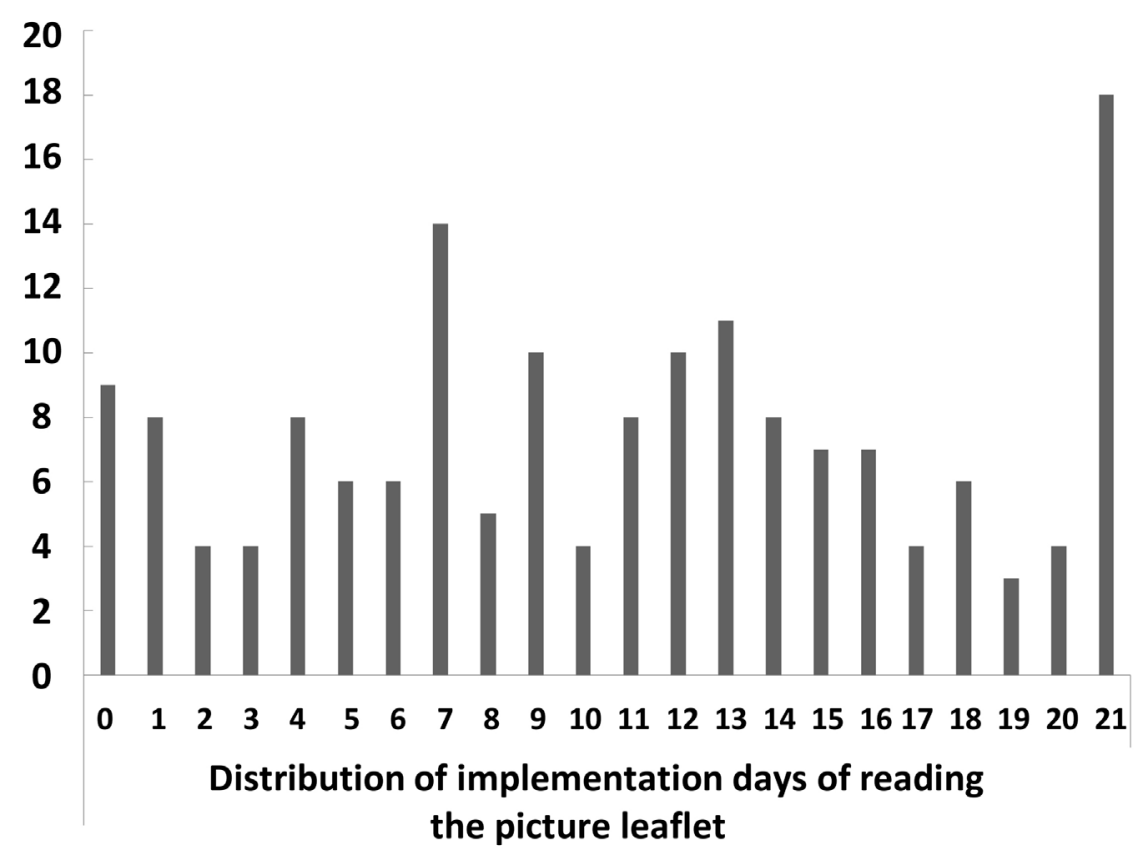

Figure 1. Implementation days of reading the picture leaflet on diurnal rhythm.

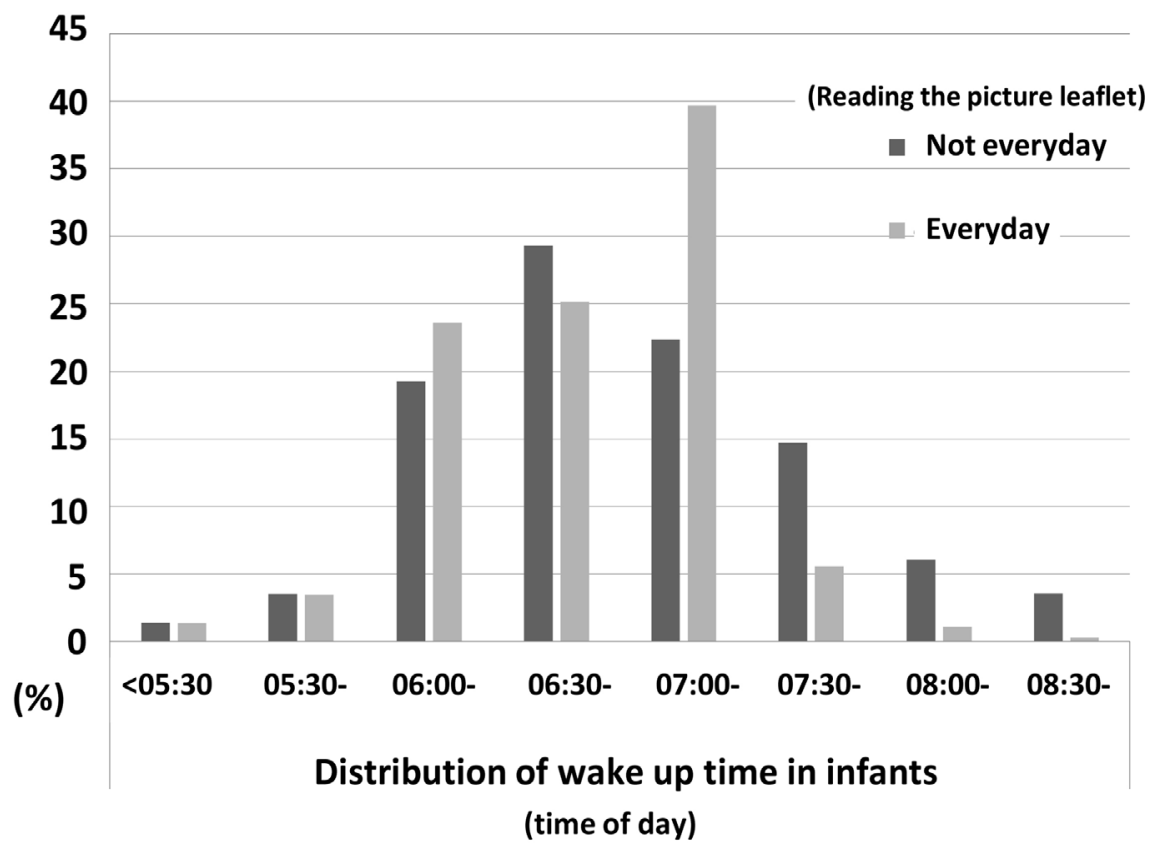

Figure 2. Comparison of wake up time of the children who had reading of the leaflet every day from their parents to the time of those who did it not all the days.

Japanese infants aged 2 - 6 years currently showed 11:00-11:30 as the total sleeping hours including naps in the daytime. In Spanish infants aged 2 - 5 years, the average value of the total sleeping hours including naps were 10.67 hours on 1987 and 10.27 hours on 2011 (de Ruiter et al., 2016). The reading of this picture leaflet may be effective for making children have longer sleep hours by $1-2$ hours. 


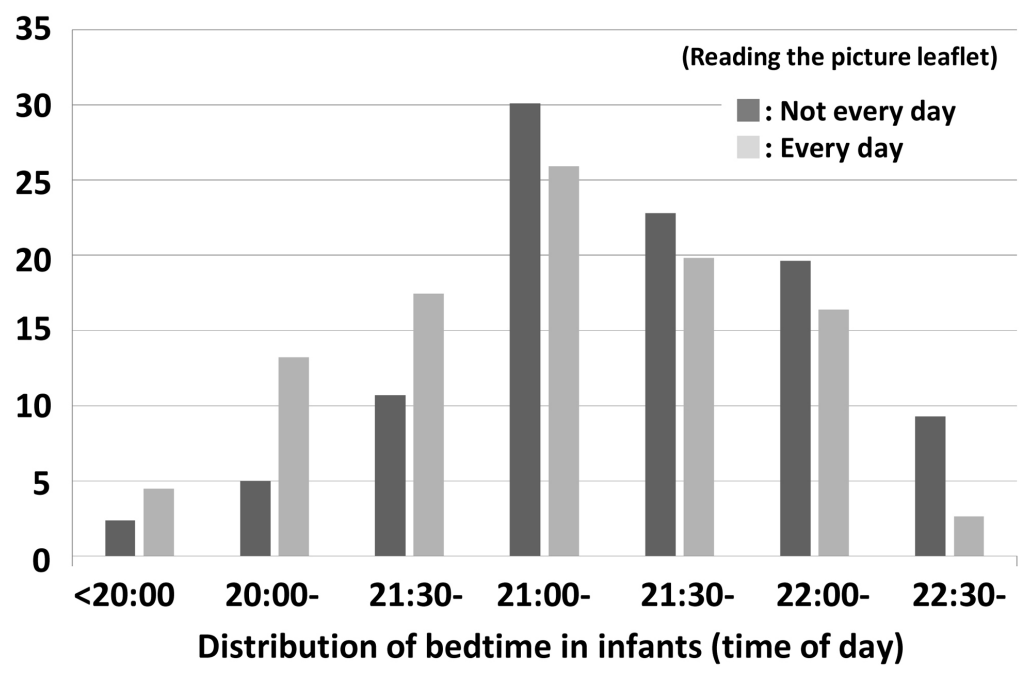

Figure 3. Comparison of bed time of the children who had reading of the leaflet every day from their parents to the time of those who did it not all the days.

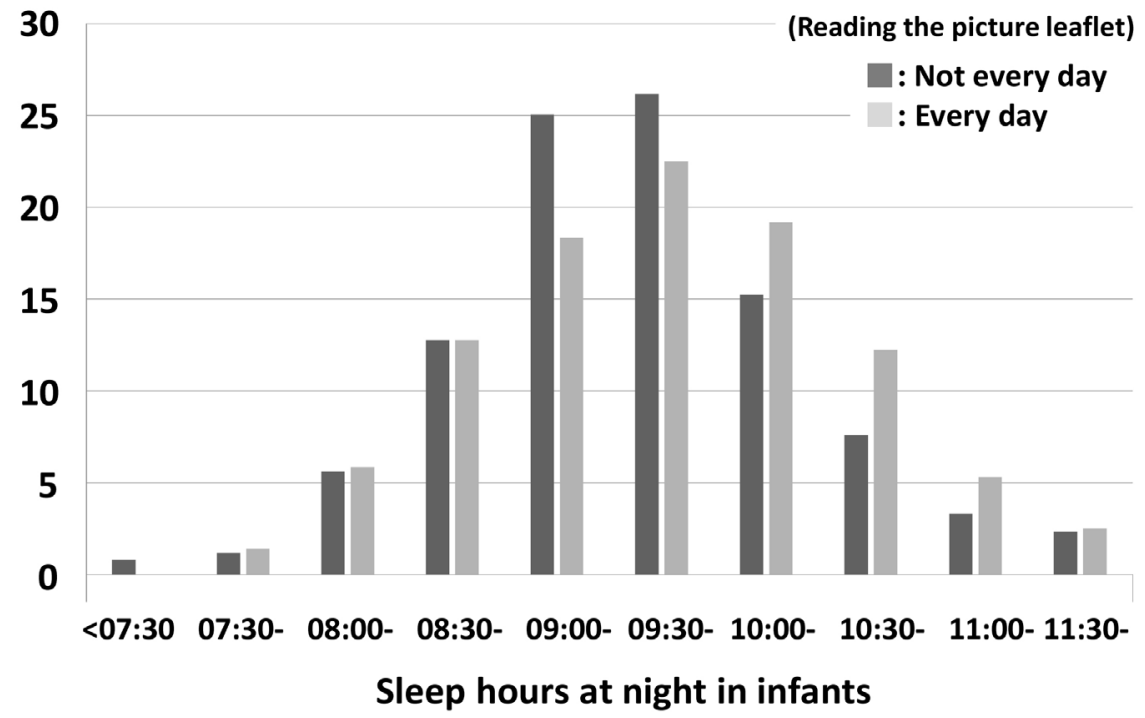

Figure 4. Comparison of the night sleep hours of the children who had reading of the leaflet every day from their parents to the time of those who did it not all the days.

In the next days of the days when the reading of the picture leaflet, the number of infants whose the wake up times later than 7:30 were apparently decreased, while the bed times after the reading days slightly shifted to earlier times. Such reading of the leaflet may be in some extent effective for children to be shifted to more morning-typed persons. However, longer intervention during a half year or one year may be more effective for promoting their morning-typed life. In the near future, the intervention study for the longer period is remained to do.

There have been no significant differences in sleep habits and the diurnal type scale scores in Japanese infants between June before intervention and October 3 months after that in 2017. Due to the seasonal change, October has shorter photoperiod than June. Because of later sun-rise, infants in October should be more 


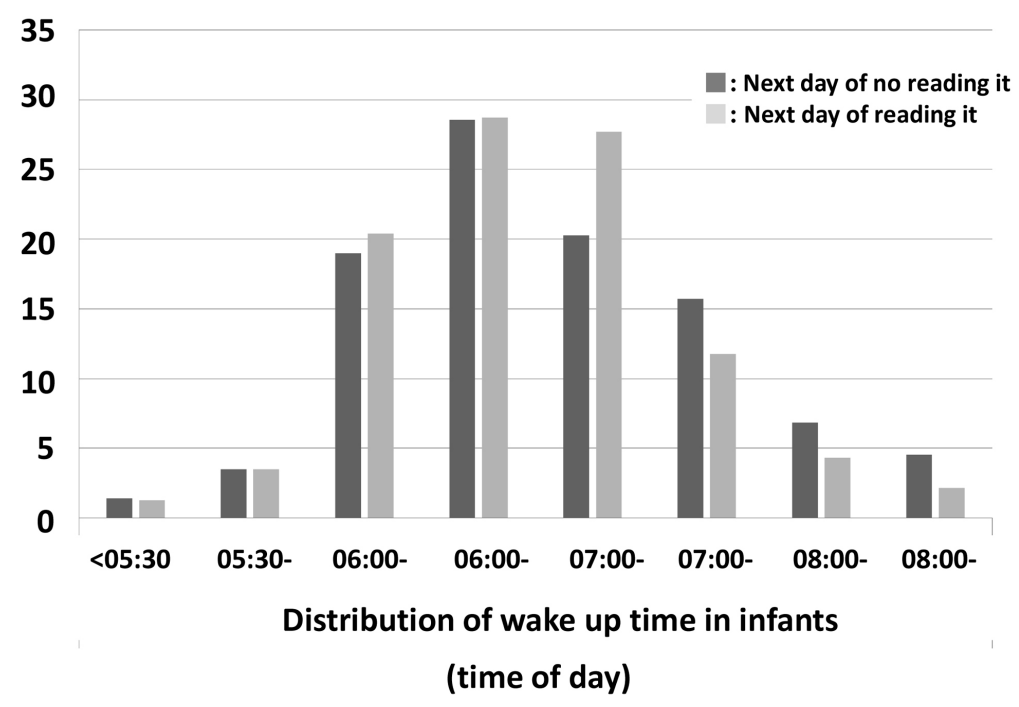

Figure 5. Comparison of wake up time in the days next to days when children had the reading of the leaflet from their parents to that in the days next to days when children did not.

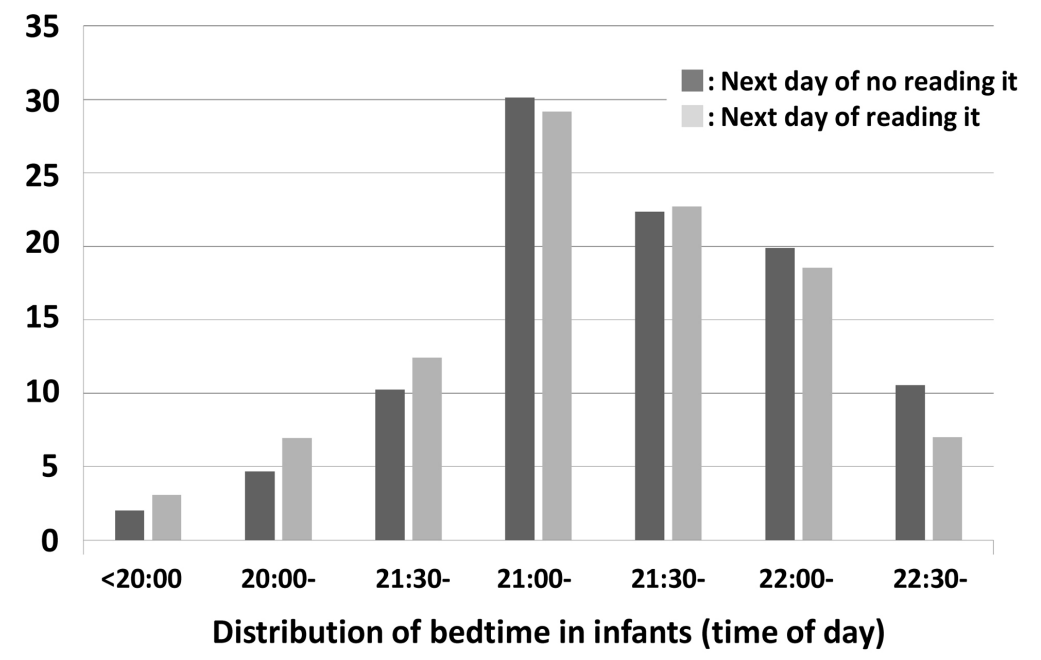

Figure 6. Comparison of bed time in the days next to days when children had the reading of the leaflet from their parents to that in the days next to days when children did not.

evening-typed and worse sleep habits than those in June at $33^{\circ} \mathrm{N}$ in Kochi. The similar sleep habits and diurnal types in June and October would show that the intervention by the new picture leaflet had some effects of shifting infants to the direction of "morning-type".

As the limitation of this study, only subjective data were available for evaluation of the effects of this new teaching material as picture leaflet. In the future, direct data using actigraph and consumption of saliva would be possible even from small children for such evaluations if there would be full understanding, by parents of small children, of the purposes of this study (promotion of health of children) and of impacts for future education. 


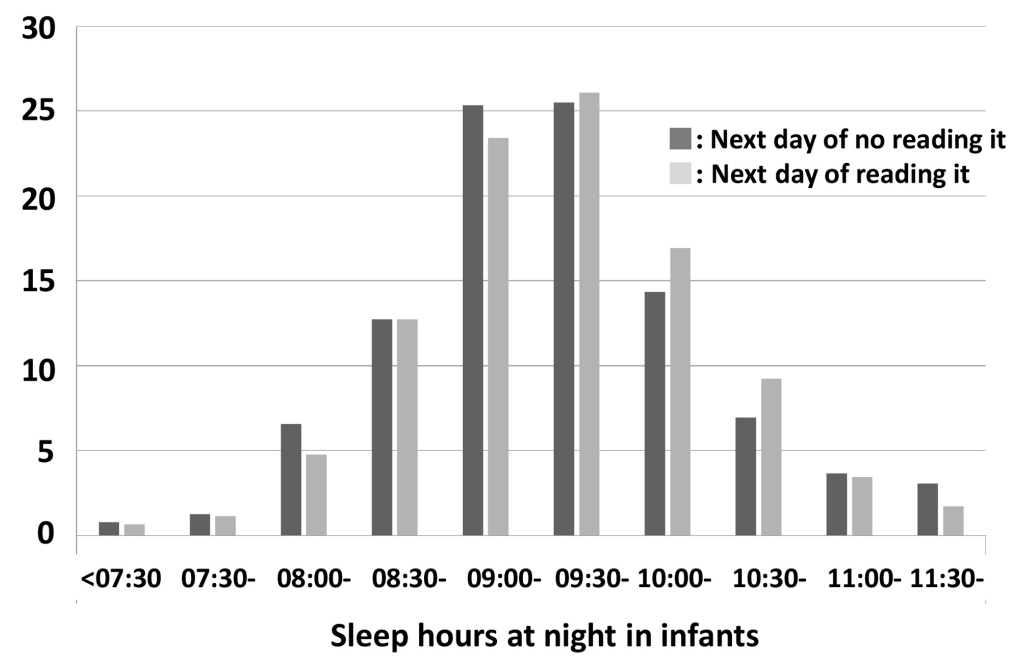

Figure 7. Comparison of sleep hours in the days next to days when children had the reading of the leaflet from their parents to that in the days next to days when children did not.

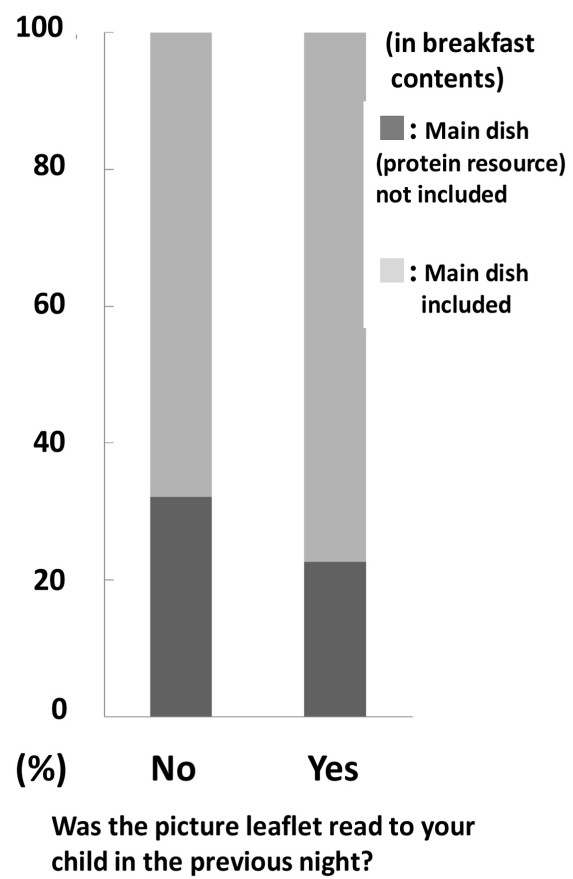

(a)

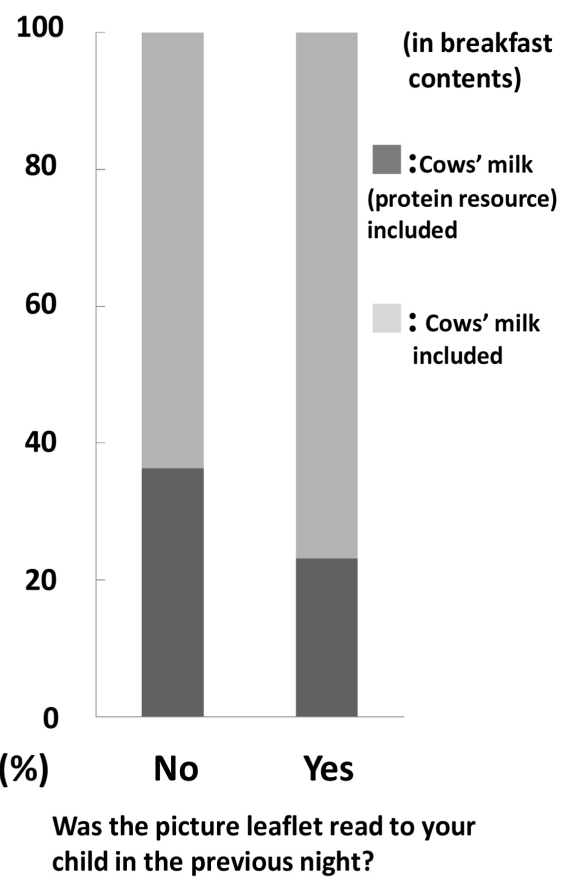

(b)

Figure 8. (a): Comparison of the rate of students who took main dish (protein resource) at breakfast in the days next to days when children had the reading of the leaflet from their parents to that in the days nest to days when children did not. (b): Comparison of the rate of students who took cow milk at breakfast in the days next to days when children had the reading of the leaflet from their parents to that in the days nest to days when children did not.

\section{Conclusion}

In conclusion, the picture leaflet seems to have a powerful intervention effect for promoting Japanese infants' "morning-typed life" based on the results of this 
study. The style of "picture book" might become teaching materials psychologically near not only to infants but to elementary and junior high schools students. The picture leaflets include detailed comparisons between morning-typed life and evening-typed life and children can easily image the detailed life styles, which should be recommended. The intervention studies also for the elementary school and junior high school students will go on using the picture leaflets for elder children in the near future.

\section{Acknowledgements}

Thanks should be due to all the participants in this study. The following financial supports have been given to this study: 1) Fund from J-Milk "Meals and Education" (To T. Harada: 2013-2014), 2) Fund from J-Milk "Research Study to Promote Health by Milk and Related Foods" (To T. Harada: 2016-2017) and 3) Funds from Japan Society for the Promotion of Science (JSPS Grant Number JP 16K01871, 2016-2019: To H. Takeuchi). This study also received a financial support from J-MILK Research Found for the support project entitled "Meals and Education" in 2016-2017 to T. Harada.

\section{References}

Akimitsu, O., Wada, K., Taniwaki, N., Krejci, M., Nakade, M., Takeuchi, H., \& Harada, T. (2013). The Relationship between Consumption of Tyrosine and Phenylalanine as Precursors of Catecholamine at Breakfast and the Circadian Typology and Mental Health in Japanese Infants Aged 2 to 5 Years. Journal of Physiological Anthropology, 32, 13. https://doi.org/10.1186/1880-6805-32-13

Au, L. E., Whaley, S., \& Rosen, N. J. (2016). Online and In-Person Nutrition Education Improves Breakfast Knowledge, Attitudes, and Behaviors: A Randomized Trial of Participants in the Special Supplemental Nutrition Program for Women, Infants, and Children. Journal of the Academy of Nutrition and Dietetics, 116, 490-450. https://doi.org/10.1016/j.jand.2015.10.012

Baxter, S. D., Royer, J. A., Hardin, J. W., Guinn, C. H., \& Smith, A. F. (2007). Fourth-Grade Children Are Less Accurate in Reporting School Breakfast than School Lunch during 24-Hour Dietary Recalls. Journal of Nutrition, Education and Behavior, 39, 126-133. https://doi.org/10.1016/j.jneb.2006.12.014

De Ruiter, I., Olmedo-Requena, R., Sanchez-Crez, J.-J., \& Jimenez-Moleon, J.-J. (2016). Changes in Sleep Duration in Spanish Children Aged 2 - 14 Years from 1987 to 2011. Sleep Medicine, 21, 145-150. https://doi.org/10.1016/j.sleep.2015.12.021

Frisvold, D. E. (2015). Nutrition and Cognitive Achievement: An Evaluation of the School Breakfast Program. Journal of Public Economics, 124, 91-104. https://doi.org/10.1016/j.jpubeco.2014.12.003

Harada, T., Itani, I., Shirakawa, S., Wada, K., Tsuji, F., Krejci, M., Kawada, T., Noji, T., Nakade, M., \& Takeuchi, H. (2015). Intervention Study Using a Leaflet Entitled 'Three Benefits of "Go to Bed Early! Get Up Early! And Intake Nutritionally Rich Breakfast!" A Message for Athletes' to Improve the Soccer Performance of University Soccer Team. Sleep and Biological Rhythms, 14, s65-s74. https://doi.org/10.1007/s41105-015-0035-5

Harada, T., Hirotani, M., Maeda, M., Nomura, H., \& Takeuchi, H. (2007). Correlation between Breakfast Tryptophan Content and Morningness-Eveningness in Japanese Infants and Students Aged 0 - 15 yrs. Journal of Physiological Anthropology, 26, 201-207. 
https://doi.org/10.2114/jpa2.26.201

Harada, T., Inoue, M., Takeuchi, H., Watanabe, N., Hamada, M., Kadota, G., \& Yamashita, Y. (1998). Study on Diurnal Rhythms in the Life of Japanese University, Junior High and Elementary School Students Including Morningness-Eveningness Preference. Bulletin of the Faculty of Education, Kochi University Series, 156, 1-91. (In Japanese)

Harada, T., Nakade, M., Wada, K., Kondo, A., Maeda, M., Noji, T., \& Takeuchi, H. (2012). Mental Health of Children from a Chronobiological and Epidemiological Point of View. In O. V. Rijeka (Ed.), Essential Notes in Psychiatry (Chapter 22, pp. 439-458). Rijeka: Intech. https://doi.org/10.5772/38801

Hochfield, T., Graham, L., Patel, L., Moodley, J., \& Ross, E. (2016). Does School Breakfast Make a Difference? An Evaluation of an In-School Breakfast Programme in South Africa. International Journal of Educational Development, 51, 1-9. https://doi.org/10.1016/j.ijedudev.2016.07.005

Kang, Y. W., \& Park, J.-H. (2016). Does Skipping Breakfast and Being Overweight Influence Academic Achievement among Korean Adolescents? Public Health and Research Perspectives, 7, 220-227. https://doi.org/10.1016/j.phrp.2016.05.004

Kawada, T., Takamori, Y., Nakade, M., Tsuji, F., Krejci, M., Noji, T., Takeuchi, H., \& Harada, T. (2016a). Effect of Drinking Cows' Milk at Breakfast in Promoting Sleep-Health in Japanese University Athletes. International Journal of Psychological Studies, 8, 154-163. https://doi.org/10.5539/ijps.v8n3p154

Kawada, T., Yamazaki, Y., Nakade, M., Noji,, Krejci, M., Takeuchi, H., \& Harada, T. (2016b). Questionnaire and Intervention Study on Effects of Drinking Cows' Milk at Breakfast on the Circadian Typology and Mental Health of Japanese Infants Aged 1 - 6 Years. Natural Science, 8, 381-396. https://doi.org/10.4236/ns.2016.89042

Lee, S. A., Park, E.-C., Ju, Y. J., Lee, T. H., Han, E., \& Kim, T. H. (2017). Breakfast Consumption and Depressive Mood: A Focus on Socioeconomic Status. Appetite, 114, 313-319. https://doi.org/10.1016/j.appet.2017.04.007

Liu, J., Hwang, W.-T., Dickerman, B., \& Compher, C. (2013). Regular Breakfast Consumption Is Associated with Increased IQ in Kindergarten Children. Early Human Development, 89, 257-262. https://doi.org/10.1016/j.earlhumdev.2013.01.006

Moore, G. F., Moore, L., \& Murphy, S. (2009). Normative and Cognitive Correlates of Breakfast Skipping in 9 - 11-Year-Old School Children in Wales. Appetite, 53, 332-337. https://doi.org/10.1016/j.appet.2009.07.012

Nakade, M., Akimitsu, O., Wada, K., Krejci, M., Noji, T., Taniwaki, N., Takeuchi, H., \& Harada, T. (2012) Can Breakfast Tryptophan and Vitamin B6 Intake and Morning Exposure to Sunlight Promote Morning-Typology in Young Children Aged 2 to 6 Years? Journal of Physiological Anthropology, 31, 11. https://doi.org/10.1186/1880-6805-31-11

Nakade, M., Hiraoka, M., Kawasaki, K., Uesato, T., Wada, K., Krejci, M., Noji, T., Taniwaki, N., Takeuchi, H., \& Harada, T. (2015). Are Obese Mothers of Children Aged 1 - 6 Years Evening-Typed? International Journal of Psychological Studies, 7, 121-128. https://doi.org/10.5539/ijps.v7n2p121

Nakade, M., Takeuchi, H., Taniwaki, N., Noji, T., \& Harada, T. (2009). An Integrated Effect of Protein Intake at Breakfast and Morning Exposure to Sunlight on the Circadian Typology in Japanese Infants Aged 2 - 6 Years. Journal of Physiological Anthropology, 28, 239-245. https://doi.org/10.2114/jpa2.28.239

Nanney, M. S., Shanafelt, A., Wang, Q., Leduc, R., Dodds, E., Hearst, M., Kubik, M. Y., Grannon, K., \& Harnack, L. (2016). Project Breakfast: Rationale, Design, and Recruit- 
ment and Enrollment Methods of a Randomized Controlled Trial to Evaluate an Intervention to Improve School Breakfast Program Participation in Rural High Schools. Contemporary Clinical Trials Communications, 3, 12-22.

https://doi.org/10.1016/j.conctc.2015.12.009

O’Neil, C. E., Bredbenner, C. B., Hayes, D., Jana, L., Klinger, S. E., \& Stephenson-Martin, S. (2014). The Role of Breakfast in Health: Definition and Criteria for a Quality Breakfast. Journal of the Academy of Nutrition and Dietetics, 114, S8-S26. https://doi.org/10.1016/j.jand.2014.08.022

Portaluppi, F., Smolensky, M. H., \& Touitou, Y. (2010). Effects and Methods for Biological Rhythm Research on Animals and Human Beings. Chronobiology International, 27, 1911-1929. https://doi.org/10.3109/07420528.2010.516381

Reeves, S., Huber, J. W., Halsey, L. G., Horabady-Farahani, Y., Ijadi, M., \& Smith, T. (2014). Experimental Manipulation of Breakfast in Normal and Overweight/Obese Participants Is Associated with Changes to Nutrient and Energy Intake Consumption Patterns. Physiology \& Behavior, 133, 130-135. https://doi.org/10.1016/j.physbeh.2014.05.015

Sampasa-Kanyinga, H., Roumeliotis, P., Farrow, C. V., \& Shi, F. Y. (2014). Breakfast Skipping is Associated with Cyberbullying and Schoolbullying Victimization. A School-Based Cross-Sectional Study. Appetite, 79, 76-82. https://doi.org/10.1016/j.appet.2014.04.007

Takeuchi, H., Yamazaki, Y., Oki, Wada, K., Noji, T., Nakade, K., Krejci, M., \& Harada, T. (2015). Effects of Chronotype and Environmental Factors upon Sleep and Mental Health in Japanese Students Aged 18 - 40 yrs. Biological Rhythm Research, 46, 771-784. https://doi.org/10.1080/09291016.2015.1048952

Takeuchi, H., Nakao, M., Kurose, W., Kawada, T., Noji, T., Nakade, M., Tsuji, F., Krejci, M., \& Harada, T. (2017). Intervention Study to Improve Meal Habit, Sleep Habit, Circadian Typology and School Marks in Japanese Elementary School Students. Journal of Sleep and Sleep Disorder Research, 1, 5.

Takeuchi, H., Wada, K., Kawasaki, K., Krejci, M., Noji, T., Kawada, T., Nakade, M., \& Harada, T. (2014). Effects of Cow Milk Intake at Breakfast on the Circadian Typology and Mental Health of Japanese Infants Aged 1 - 6 Years. Psychology, 5, 172-176. https://doi.org/10.4236/psych.2014.52027

Torsvall, L., \& Åkerstedt, T. (1980). A Diurnal Type Scale: Construction, Consistency and Validation in Shift Work. Scandinavian Journal of Work, Environment \& Health, 6, 283-290. https://doi.org/10.5271/sjweh.2608

Wada, K., Yata, S., Akimitsu, O., Krejci, M., Noji, T., Nakade, M., Takeuchi, H., \& Harada, T. (2013). A Tryptophan-Rich Breakfast and Exposure to Light with Low Color Temperature at Night Improve Sleep and Salivary Melatonin Level in Japanese Students. Journal of Circadian Rhythms, 11, 4. http://www.jcircadianrhythms.com/content/11/1/4 https://doi.org/10.1186/1740-3391-11-4

Yoshimura, E., Hatamoto, Y., Yonekura, S., \& Tanaka, H. (2017). Skipping Breakfast Reduces Energy Intake and Physical Activity in Healthy Women Who Are Habitual Breakfast Eaters: A Randomized Crossover Trial. Physiology \& Behavior, 174, 89-94. https://doi.org/10.1016/j.physbeh.2017.03.008 


\section{Appendix 1}

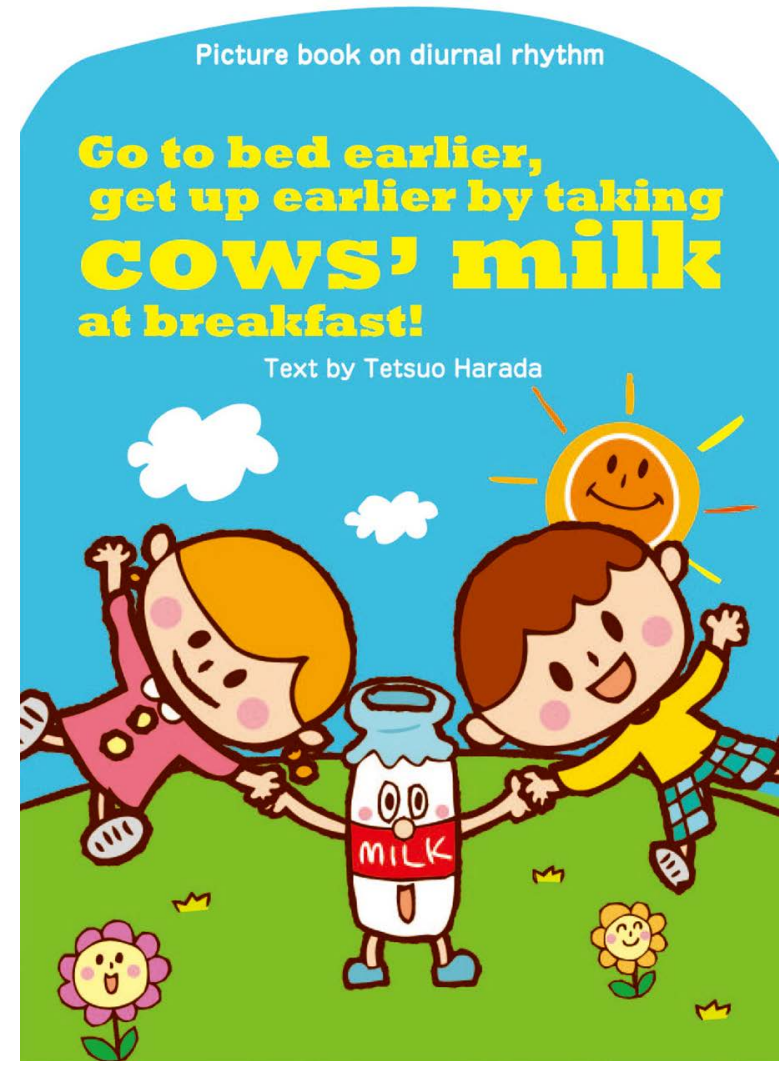

(One day of "morning-typed" infant)

A morning-typed infant gets up early in the morning.

$\mathrm{He}$ (or She) switches on the fluorescent lamp in his (or her) room and open the curtain.
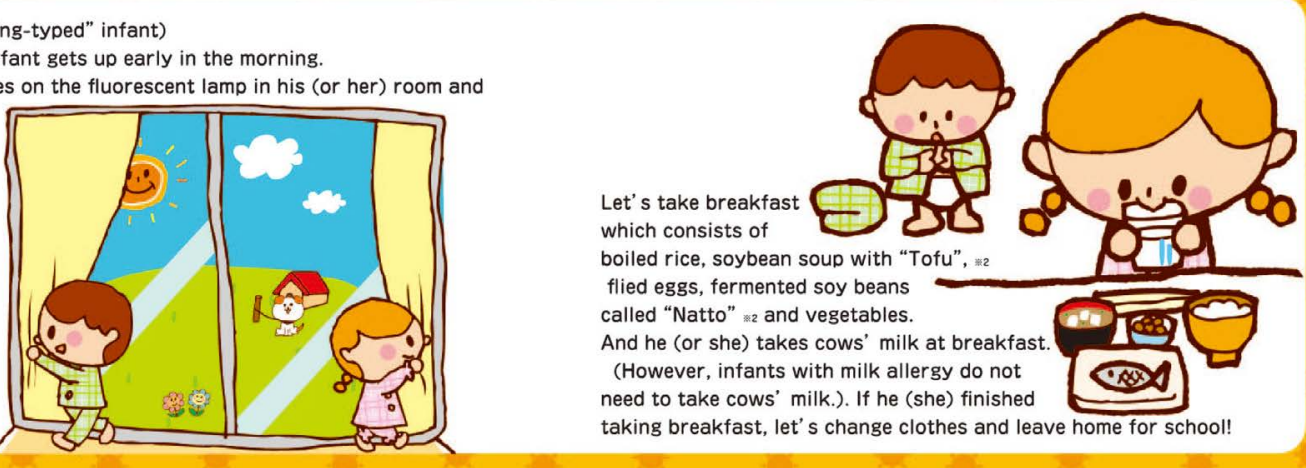

(One day of "evening-typed" infant) An evening-typed infant is not well being in the morning, and he (or she) is not well consciousness after getting up.

$\mathrm{He}$ (or she) takes long time after getting up till being back to ordinary alertness.
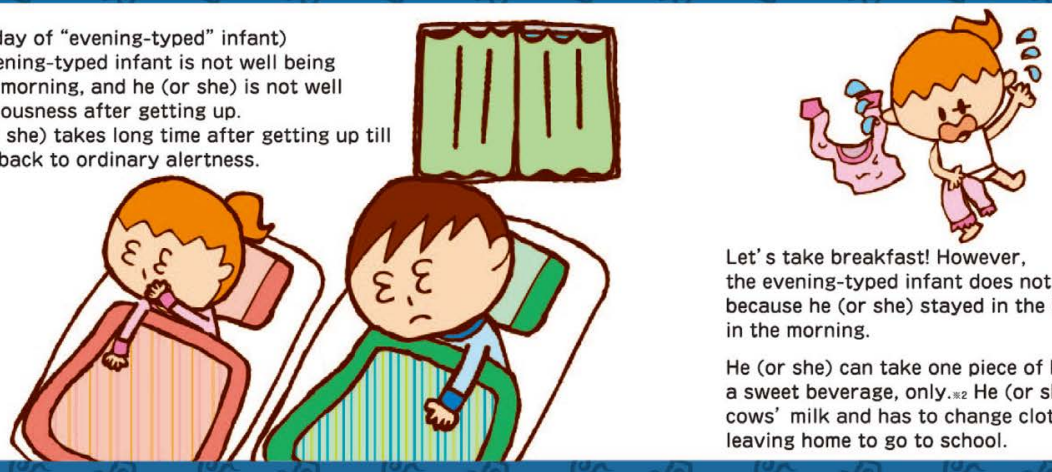
Let's take breakfast! However,
the evening-typed infant does not have appetite because he (or she) stayed in the bed late in the morning.

He (or she) can take one piece of bread and

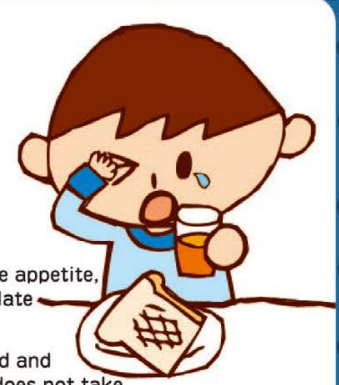
a sweet beverage, only $\mathrm{He}$ (or she) does not tak cows' milk and has to change clothes quickly for leaving home to go to school. 
During moving from home to nursery schoo I

(or kindergarten), he (or she) is exposed to sun-lights.

After arriving at the nursery school (or kindergarten).

he (or she) is playing out side in the garden of the

nursery school (or kindergarten) $*$

The infants who are morning-typed are well-being and powerful physically and mentally.*3

After the nursery school (or kindergarten), one of family members pick him (or her)

up and go to home.
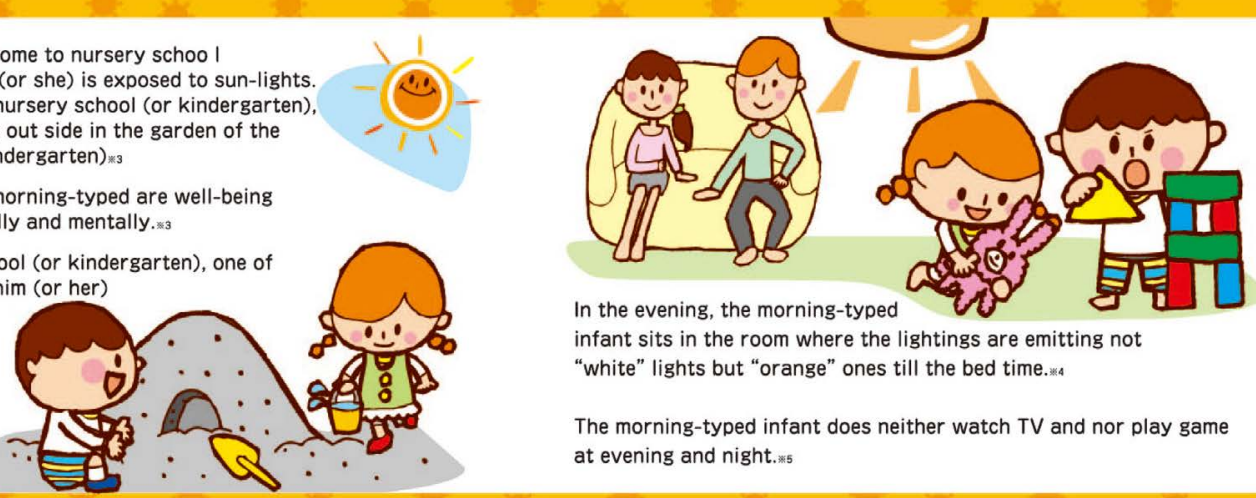

infant sits in the room where the lightings are emitting not

"white" lights but "orange" ones till the bed time.*.

The morning-typed infant does neither watch TV and nor play game at evening and night.*s

During moving from home to nursery school (or kindergarten),

he (or she) is sleeping in the car or buse.*3 After arriving at the

nursery school (or kindergarten), he (or she) is resting in the room of

nursery school (or kindergarten).

The infants who are evening-typed are neither well-being and

nor powerful physically and mentally*3 there in the

nursery school (or kindergarten).

After the nursery school (or kindergarten), one of family members pickes him (or her) up and go to home.
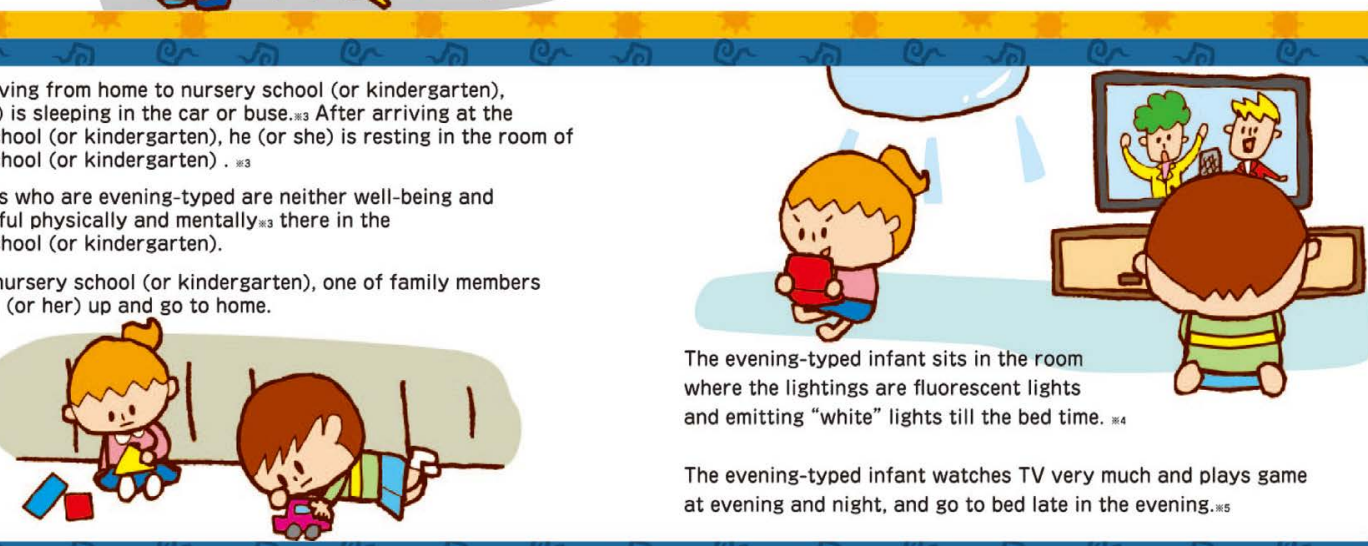

and emitting "white" lights till the bed time. *4

The evening-typed infant watches TV very much and plays game at evening and night, and go to bed late in the evening.ws

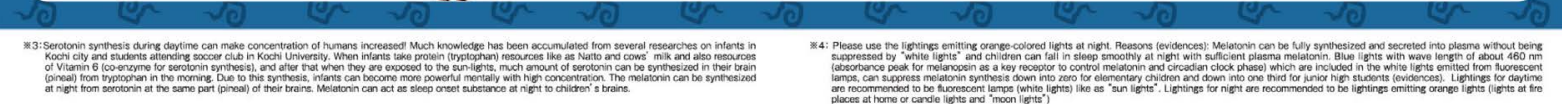

The morning-typed infant goes to bed before 20:00. At latest.

he (or she) goes to bed before 21:00.
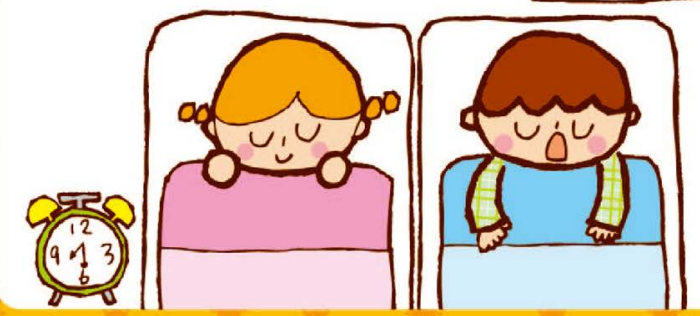

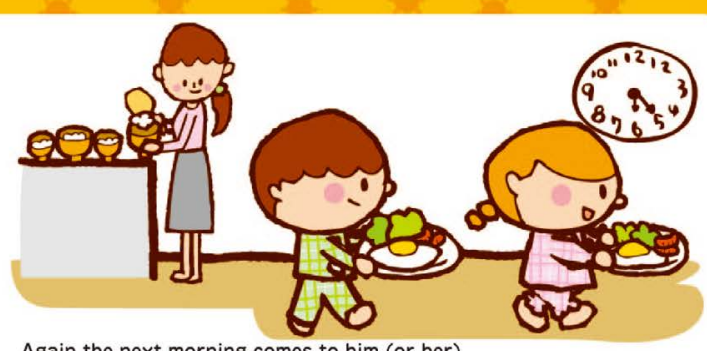

Again the next morning comes to him (or her).

The morning-typed infant wakes up

naturally without any equipment at 06:00.

$\mathrm{He}$ (or she) is wellbeing and powerful physically and mentally in the morning.
The evening-typed infant goes to bed about 22:30. At latest, he (or she) goes to bed 23:00 or even later.

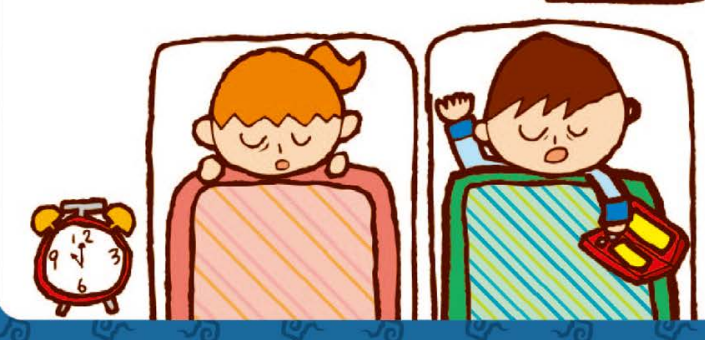

Again the next morning comes to him (or her). The evening-typed infant cannot wake up without some equipment at 06:00.

$\mathrm{He}$ (or she) is neither wellbeing mentally and nor powerful physically in the morning.

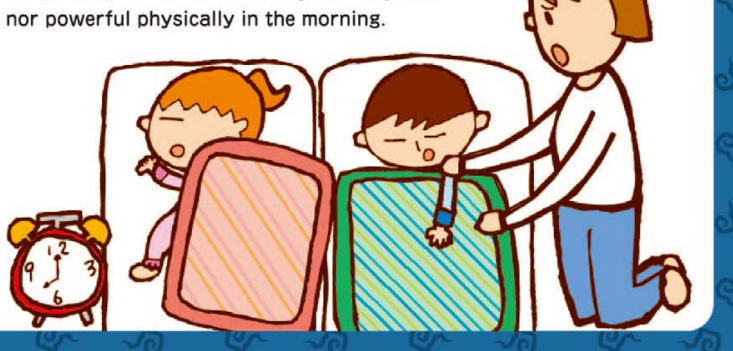

and 


\section{Let's take cows' milk at breakfast!}

When infants take cows' milk at breakfast and then are exposed to sun-lights, an amino acid "tryptophan-man" included in proteins of cows' milk can be changed to "serotonin-man" in their bodies.*2 *3

The serotonin-man can be changed to "melatonin-man" at night in the body under the "orange-colored" lights in their bodies.*4

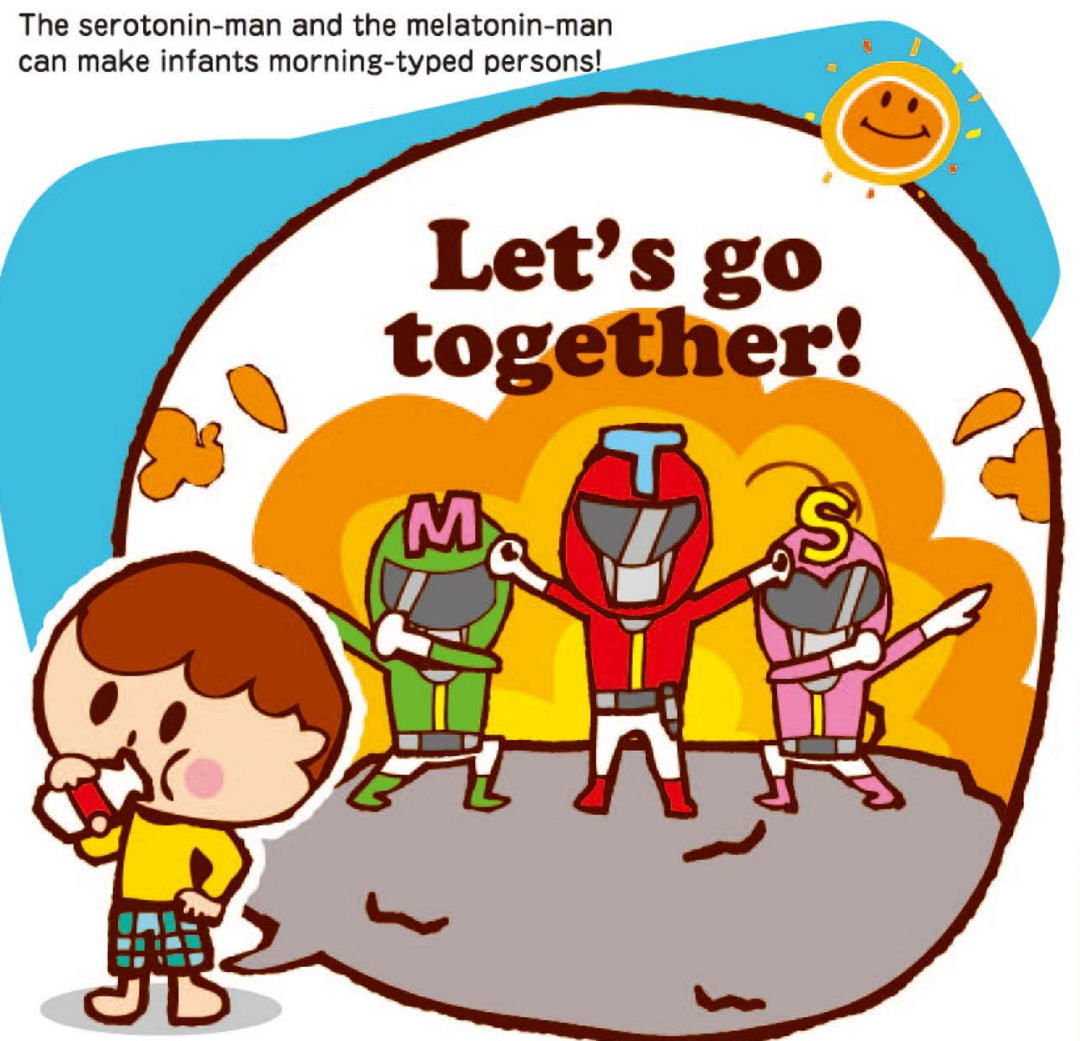

This work was supported by J-Milk Research Fund for "Meals and Education" in 2016-2017.

Published by "Research project about sleep habits and diurnal-rhythms in the life of Japanese university, junior high, elementary school students and infants including morningness-eveningness preference" Edited by Tetsuo Harada" and Nozomi Taniwakiz)

1) Professor of Environmental Physiology at Graduate School of Integrated Arts and Sciences, Kochi University, 2) Vice-principal of Kindergarten affiliated to Faculty of Education, Kochi University

Appendix 2: English Text of the Picture Book Entitled “Going to Bed Earlier, Getting up Earlier by Taking Cows' Milk at Breakfast Which Is for Small Children (Infants)

Picture book on diurnal rhythm

Title: Go to bed earlier, get up earlier by taking cows' milk at breakfast! (Text by Tetsuo Harada)

One day of "morning-typed" infant)

A morning-typed infant gets up early in the morning. He (or She) switches on the fluorescent lamp in his (or her) room and open the curtain ${ }^{1)}$. Let's take breakfast which consists of boiled rice, soybean soup with "Tofu" ${ }^{2}$, flied eggs, fermented soy beans called "Natto"2) and vegetables. And he (or she) takes cows' milk at breakfast. (However, infants with milk allergy do not need to take cows' 
milk.). If he (she) finished taking breakfast, let's change clothes and leave home for school!

During moving from home to nursery school (or kindergarten), he (or she) is exposed to sun-lights. After arriving at the nursery school (or kindergarten), he (or she) is playing our side in the garden of the nursery school (or kindergarten $)^{3)}$.

The infants who are morning-typed are well-being and powerful physically and mentally ${ }^{3}$.

After the nursery school (or kindergarten), one of family members pick him (or her) up and go to home.

In the evening, the morning-typed infant sits in the room where the lightings are emitting not "white" lights but "orange" ones till the bed time $e^{4)}$

The morning-typed infant does neither watch TV and nor play game at evening and night ${ }^{5}$.

The morning-typed infant goes to bed before 20:00. At latest, he (or she) goes to bed before $21: 00^{6}$.

Again the next morning comes to him (or her). The morning-typed infant wakes up naturally without any equipment at 06:00. He (or she) is wellbeing and powerful physically and mentally in the morning.

(One day of "evening-typed" infant)

An evening-typed infant is not well being in the morning, and he (or she) is not well consciousness after getting up. He (or she) takes long time after getting up till being back to ordinary alertness.

Let's take breakfast! However, the evening-typed infant does not have appetite, because he (or she) stayed in the bed late in the morning. He (or she) can take one piece of bread and a sweet beverage, only ${ }^{2}$. He (or she) does not take cows' milk and has to change clothes quickly for leaving home to go to school.

During moving from home to nursery school (or kindergarten), he (or she) is sleeping in the car or buse ${ }^{3)}$. After arriving at the nursery school (or kindergarten), he (or she) is resting in the room of nursery school (or kindergarten) ${ }^{3)}$.

The infants who are evening-typed are neither well-being and nor powerful physically and mentally $y^{3)}$ there in the nursery school (or kindergarten).

After the nursery school (or kindergarten), one of family members pickes him (or her) up and go to home.

The evening-typed infant sits in the room where the lightings are fluorescent lights and emitting "white" lights till the bed time ${ }^{4}$.

The evening-typed infant watches TV very much and play game at evening and night, and go to bed late in the evening ${ }^{5)}$.

The morning-typed infant goes to bed about 22:30. At latest, he (or she) goes to bed 23:00 or even later ${ }^{6}$.

Again the next morning comes to him (or her). The evening-typed infant cannot wake up without some equipment at 06:00. He (or she) is neither wellbeing mentally and nor powerful physically in the morning. 


\section{Let's take cows' milk at breakfast!}

When infants take cows' milk at breakfast and then are exposed to sun-lights, an amino acid "tryptophan-man" included in proteins of cows' milk can be changed to "serotonin-man" in their bodies",3).

The serotonin-man can be changed to "melatonin-man" at night in the body under the "orange-colored" lights in their bodies").

The serotonin-man and the melatonin-man can make infants morning-typed persons!

1) Let's be exposed to sun-lights or lights from fluorescent lamp just after waking up.

In the summer season, please use a thin curtain for sun lights coming through it into the room. In the winter, please switch on all the lightings as fluorescent lamps emitting white lights in the morning. Reasons (evidences): Core body temperatures in humans fluctuate with diurnal rhythms with peak at 15:00-16:00 and with bottom at 04:00-05:00. The exposure to sun-lights or white lights during 3 or 4 hours from the bottom time is known to make the phase of circadian clock in-advance.

2) We can recommend cows' milk and fermented soy beans called Natto as breakfast menu. Because $98 \%$ of nutrition in Natto can be digested and absorbed into the body, much amount of tryptophan as a precursor of serotonin can be took into the body from only small amount of Natto. However, cows' milk is the best recommendation, because it can be easily bought (cheep and any kinds of shops we can get) and taken. Let's drink cows' milk like as Japanese tea in the morning! Our research on the infants living in Kochi city showed that the infants who took only cows' milk at the breakfast were more morning-typed than those taking carbohydrate only. Of course, bacon, dry fishes and cooked fishes and so on are effective for the serotonin synthesis like as cows' milk and Natto. Anyway, please add one dish (as protein resource) into breakfast menu. Most of foods as protein-resources include much amount of Vitamin 6, and are effective for serotonin synthesis themselves. Vegetables and fruits are also effective for serotonin synthesis as Vitamin 6 resources.

3) Serotonin synthesis during daytime can make concentration of humans increased! Much knowledge has been accumulated from several researches on infants in Kochi city and students attending soccer club in Kochi University. When infants take protein (tryptophan) resources like as Natto and cows' milk and also resources of Vitamin 6 (co-enzyme for serotonin synthesis), and after that when they are exposed to the sun-lights, much amount of serotonin can be synthesized in their brain (pineal) from tryptophan in the morning. Due to this synthesis, infants can become more powerful mentally with high concentration. The melatonin can be synthesized at night from serotonin at the same part (pineal) of their brains. Melatonin can act as sleep onset substance at night to children's brains.

4) Please use the lightings emitting orange-colored lights at night. Reasons (evidences): Melatonin can be fully synthesized and secreted into plasma with- 
out being suppressed by "white lights" and children can fall in sleep smoothly at night with sufficient plasma melatonin. Blue lights with wave length of about $460 \mathrm{~nm}$ (absorbance peak for melanopsin as a key receptor to control melatonin and circadian clock phase) which are included in the white lights emitted from fluorescent lamps, can suppress melatonin synthesis down into zero for elementary children and down into one third for junior high students (evidences). Lightings for daytime are recommended to be fluorescent lamps (white lights) like as "sun lights". Lightings for night are recommended to be lightings emitting orange lights (lights at fire places at home or candle lights and "moon lights")

5) Please make the duration of watching TV and playing game for infants limited within 1 hour. The number of children to play game actively at night, increases from the middle grade of elementary school in Japan. When they watch TV and play game more than 1 hour per night, sleep health and mental health of infants and elementary school students were worse based on research evidences which showed that watching TV and playing game every day had negative effects on their health. Please make off-day for watching TV and playing game for infants. The blue lights emitted from TV displays can lead to suppress the melatonin synthesis and disturb the onset of sleep for infants. The TV watching at night should be avoided for small children.

6) Timing for growth hormone synthesis and secretion into the body Timing of secretion of growth hormone can be about 20:00-21:00 for children and about 23:00 for adults (directly caused by body temperature decrease). If infants and adults awaken still in this time, the amount of growth hormone can be decreased. The growth hormone is known to be secreted at the timing of slow wave sleeps (Stages 3 and 4) in Non-REM sleep. Therefore, being awaken at late time can lead to lower growth for children and lead not to be repaired of damaged tissues (related to beauty and aging) for adults.

\section{Scientific Research Publishing}

Submit or recommend next manuscript to SCIRP and we will provide best service for you:

Accepting pre-submission inquiries through Email, Facebook, LinkedIn, Twitter, etc. A wide selection of journals (inclusive of 9 subjects, more than 200 journals)

Providing 24-hour high-quality service

User-friendly online submission system

Fair and swift peer-review system

Efficient typesetting and proofreading procedure

Display of the result of downloads and visits, as well as the number of cited articles

Maximum dissemination of your research work

Submit your manuscript at: http://papersubmission.scirp.org/

Or contact psych@scirp.org 